tion. The "new schools," containing the museum and lecturerooms, are not the less excellent because money has not been spent on elaborate exterior. Even to compare the museums of Cambridge en masse with those of Oxford, suggests that "Lumbricus," when he dwelt among us, had his range of vision sadly limited, - perhaps through fear of the "early bird." I shall not here enlarge on the riches of our geological, mineralogical, botanical, pathological, and zoological museums; it is only necessary to say that the last-mentioned collection excels in its comparative anatomy series, its peculiar excellence lying in the comparative anatomy of vertebrata. With this grand series "Lumbricus," of course, - has nothing in common.

"Lumbricus" says we have no "Professor of Experimental Physics" at Cambridge. It is true that no professor bears that exact title, but has "Lumbricus" never heard of Willis, Professor of Natural and Experimental Philosophy, whose views on the physiology of the larynx have been so universally accepted that he is quoted in every European work on physiology? or again, has "Lumbricts" never heard of Professor Stokes, whose lectures on applied mathematics are no less the admiration of his class than his grand discovery of the different forms of cruorine is of the scientific world? With two such lecturers on experimental physics, it is not surprising to hear that Oxford, unable to compete with us, is obliged to choose a Cambridge man to fill her professorial chair. But these are not our only professors in physical science known to the world. Our Professor of Mineralogy is well known throughout Europe; and his manual is indispensable to every mineralogist. Our Professor of Chemistry has no rival as a lecturer in the metropolis. Professors Sedgwick and Adamsnames not likely to be forgotten,-also belong in part to physical science. In biological science I need only enumerate the Professors Babington, Humphry, and Newton, to remind your readers that we do not lack energetic workers in this department.

"Cambridge has sacrificed the development of physical science to the foundation of a medical school." No piece of information which "Lumbricus" gives us is so astounding as this. Would that it were really true. To all who look at the profession of medicine in the right light, this would be indeed good news. If all the intellectual power which is being put forth in this University to grapple the problems of physical science were concentrated on the study of medicine, what might not be the result ! Surely, the profession would at least accuire a differert status, and we should no longer find physic shading off imperceptibly through honest humbug to the absurdities of homoepathy, or still find surgery highly esteemed which only combines the skill of the barber and butcher.

But "Lumbricus" looks at medicine with a jaundiced eye -the expression in this case is unfortunate, as "Lumbricus" has nothing homologous to a liver, and his eyes are aberrant. Besides, if he had such organs in such a state, he might unwillingly contribute to our knowledge of hepatic disease. But to be serious, "Lumbricus" has no wish to hide the fact that medicine is in disrepute in Oxford. Dissection of human bodies is not in accordance with "the traditions of University life" -it does not aid in the "higher education" gained by the cleaner work of dissecting snails and earthworms. I had before heard that to be a medical student at Oxford was not quite the thing. "Alas! poor "Lumbricus" fears lest the caws should peck at him. As a home-thrust to "Lumbricus" I would say, in the words of a Quarterly Reviewer, "Let him remember how much abstract scientific work is annually produced by the medical profession."

It has been noticed above, that "Lumbricus" points with scorn at the poverty of the University of Cambridge. I can only say that I wish the Colleges were equally poor. If you eould see before you the great blank which represents the life of the majority of the grey-headed resident College fellowsand see, as may here be plainly seen, that this want of energy is mainly due to their being able without any exertion on their part to fare sumptuously every day-if, I say, you could see this, you would think it no bad thing even if the science student of Cambridge has a severe struggle for existence.

In conclusion, $I$ would say, as one attached to this educational villus who cannot remain unaffected during intestinal complaints, that though, from inherent and adherent properties, I am unable to work through and through the earth, still I may be allowed to say that here one has a plentiful supply of pabulum in a favourable condition for assimilation.

Cambridge, Jan. 1868. I am, Sir, yours obediently,

Cellula.

\section{IODIDE OF POTASSIUM IN LARGE DOSES.}

To the Editor of THe Larcet.

SrR, - During the years 1858-59, whilst a student at the Edinburgh University, I performed a series of experiments in order to test the effects of different drugs upon myself. In THE LaNCET of April 14th, 1860, you did me the honour of publishing the result of my observations on the iodide of potassium. To that report I beg to refer Dr. Julius Pollock for further details. Suffice it here to state that, with gradually increasing doses, I was enabled to take one ounce per diem of that drug with no other effects than slight catarrhal symptoms. I at that time thought that, in the treatment of syphilis, chronic rheumatism, \&c., all the good effects of the drug might be ob. tained by small doses; but further experience has convinced me that large doses - twenty or even thirty grains-are not only well borne, but are frequently required in order to effeet a cure. I remain, Sir, yours \&c.,

Maida-hill, Dec. 23rd, 1867.

R. S. Sissor, M.D.

\section{To the Editor of THE LANCET.}

SrR, - The suggestions of Dr. Pollock and Sir Henry Thompson in late numbers of THE LANCE', as to the treatment of secondary and tertiary syphilitic affections by large doses of iodide of potassium, are extremely valuable, and the whole question is one of great practical importance ; and as the subject has now been mooted in your columns, it may not be uninteresting to add other experience as to these of ten intractable forms of disease.

Like most other practitioners, I also have continually found. the iodide, when given in small or moderate doses, fail to arrest the ravages of ulcerative secondary or of tertiary syphilis, but I have for some time past been aware of the sin. gular increase to the efficacy of this drug which is produced by combining with it a salt of iron, or, what I find to be better still, a double salt of iron and quinine. In this way I find that a dose not exceeding eight to ten grains of the iodide of potassium, with the same quantity of the citrate of iron and quinine, rarely fails to stay the progress of the disease, and has repeatedly, in my hands, been at once and progressively effective, when the same dose of the iodide by itself has exerted little or no power over its progress. Indeed, so frequently has this been the case, that my rule now is to begin at once with the compound mixture, instead of with the iodide alone, or in solution in the usual bitter infusion.

Iron has long been known to be very useful in tertiary and some secondary affections; and I doubt not that its action is to counteract and rectify the blood cachexia which is so markedly present in these cases. But I believe, also, that the quinine has its special advantage over other bitters; in all probability as more markedly opposing undue destruction of tissue. But whatever the theory of their action, I can state that my case-books now show many instances of most successful results from the above method, after the iodide alone, even in good doses, had been given in vain; and I have at this very time two patients under my care in the Norfolk and Norwich Hospital, suffering from severe tertiary affections, who are rapidly receiving the most marked benefit from this mode of treatment, of whom one-a woman-has suffered for nine years from ulceration of the nose, hard palate, and pharynx, and has been treated in vain at one-if not two-public hospitals, where it may be safely inferred she has taken the iodide of potassium in at least the usual doses.

Norwich, Dec. 31, 1867

$$
\text { I am, Sir, your obedient servant, }
$$

\section{ON IITHOTOMY BY A SEMILUNAR EXTERNAL INCISION.}

To the Editor of THE LANCET.

SIR,-The very interesting lecture by Sir W. Fergusson on the 4th instant, and the communication by Mr. Erichsen on the 11th instant, pointing out the value of a semilunar external incision in lithotomy as an important improvement-being, in fact, a combination of the "bilateral" and "lateral" operations, and having many advantages, - tempt me to say that, during the years 1846-8, the late J. A. Ransome, Esq., very constantly operated, at the Manchester Infirmary, in the way 